\title{
A TECHNIQUE FOR REARING MEGAPHRAGMA SPP., AN EGG PARASITOID OF GREENHOUSE THRIPS
}

\author{
A. CHHAGAN \\ Auckland University, c/- HortResearch, Private Bag 92169, Auckland \\ Corresponding author: achhagan@hortresearch.co.nz.
}

Greenhouse thrips (Heliothrips haemorrhoidalis Bouché) (Thysanoptera: Thripidae) affects many horticultural crops in New Zealand. Only a few natural enemies have been reported for this pest, including parasitoids belonging to the genus Megaphragma (Hymenoptera: Trichogrammatidae). Megaphragma spp. specimens were first collected in the 1920s in Hawaii, and subsequently found to be parasitoids of greenhouse thrips in 1937. Megaphragma spp. was first recorded in New Zealand in 1979. A technique for rearing Megaphragma spp. was developed to investigate the biology of the species. Twenty adult greenhouse thrips were placed onto each of 10 unripe lemons. The lemons were placed into a ventilated plastic container and maintained at $23 \pm 2^{\circ} \mathrm{C}$ for four days. Each week for 4 weeks, 25 Megaphragma spp. adults removed from field-collected kiwifruit leaves were placed into the container. Fresh lemons were added every 24 days and any deteriorated lemons were removed. The colony was maintained in a perspex incubator at $23 \pm 2^{\circ} \mathrm{C}$. The developmental time of Megaphragma spp. from egg to adult averaged 30 days $( \pm 0.5 \mathrm{SE})$. Under the same conditions, greenhouse thrips had a mean developmental time of 36.5 days $( \pm 0.7 \mathrm{SE}$ ). This rearing technique was an effective method for establishing a laboratory colony of Megaphragma spp.

\section{ELECTRONICALLY MONITORED FEEDING BEHAVIOUR OF MYZUS PERSICAE ON FOUR DIFFERENT HOST PLANTS}

\author{
M. SANDANAYAKA and P. CONNOLLY \\ The Horticulture and Food Research Institute of New Zealand Ltd, \\ Private Bag 92169, Auckland, New Zealand \\ Corresponding author: msandanayaka@hortresearch.co.nz
}

The electronic feeding monitor was first developed by McLean and Kinsey in 1964 to study the feeding behaviour of piercing-sucking insects. This technique was used to study the behavioural differences in probing and feeding behaviour of Myzus persicae, which is an economically important pest of a number of New Zealand and international crops. The seedling stages of cabbage, chinese cabbage, tobacco and tomato plants were tested using adult aphids. All behavioural changes observed from first probe to phloem ingestion on adaxial and abaxial surfaces of the leaves were recorded for four hours using the electrical penetration graph. Time spent by aphids in the non-probing phase (time taken to the first probe), pathway phase (time to reach phloem) and phloem phase (time for phloem salivation and ingestion) were compared between the two leaf surfaces of each plant type. The surfaces had a significant effect $(\mathrm{P}<0.05)$ on the proportion of time spent in the non-probing and the phloem phases for cabbage, but not for the other plants. The information gathered from this study will allow further studies concerning the acquisition and inoculation of plant pathogens by $M$. persicae and other aphids. 